\title{
Comparison of Acid and Bile Tolerances, Cholesterol Assimilation, and CLA Production in Probiotic Lactobacillus acidophilus Strains
}

\author{
Sejong Oh, Chang Hun Chai ${ }^{1}$, Sae Hun Kim¹, Young-Jun Kim², Hyung S. Kim³, and Randy W. Worobo4* \\ Division of Animal Science, Chonnam National University, Gwangju 500-757, Korea \\ ${ }^{1}$ Divison of Food Science \& Technology, Korea University, Seoul 136-701, Korea \\ ${ }^{2}$ Department Food \& Biotechnology, Korea University, Sejong 339-700, Korea \\ ${ }^{3}$ Culture Systems Inc., Mishawaka, IN 46545, USA \\ ${ }^{4}$ Department of Food Science \& Technology, Cornell University, Geneva, NY 14456, USA
}

\begin{abstract}
This study aimed to compare the probiotic characteristics of twelve strains of Lactobacillus acidophilus including cholesterol assimilation and conjugated linoleic acid (CLA) production. Cholesterol assimilation exhibited some variation among L. acidophilus strains, which could be classified into three groups based on their assimilation levels $(p<0.05)$. The high cholesterol assimilation group exhibited a significantly higher tolerance to 0.3 and $0.5 \%$ bile acid than the low cholesterol assimilation group $(p<0.05)$. Cholesterol assimilation showed positive correlation with $0.5 \%$ bile tolerance, and a negative correlation with acid tolerance $(p<0.01)$. Glycocholate deconjugation activity showed no relationship with cholesterol assimilation, whereas taurocholate deconjugation activity was shown to have negative correlation with cholesterol assimilation $(p<0.05)$. CLA production by L. acidophilus strains exhibited a wide variation, ranging from 2.69 to $5.04 \mathrm{mg} / \mathrm{g}$ fat. CLA production of $L$. acidophilus GP1B was the highest among the tested strains, but there was no evidence for differences in CLA production in strain specificity. Based on these results, the cholesterol assimilation of L. acidophilus strains may not be related to deconjugation activity, but may in-fact be attributed to their bile-tolerance.
\end{abstract}

Key words: probiotics, Lactobacillus acidophilus, cholesterol, conjugated linoleic acid

\section{Introduction}

Lactobacillus acidophilus strains are normal inhabitants of the human body and are considered to be probiotic cultures, due to the various health benefits they provide, in a symbiotic relationship with humans. Bile and acid tolerances are important criteria for probiotic cultures enabling them to survive in the gastrointestinal tracts (Havenaar et al., 1992). The small intestine and colon contain relatively high concentrations of bile acids which can inhibit growth or kill many bacteria. Therefore, it is essential that LAB intended for use as probiotic cultures, should be tolerant of bile acids (Gilliland, 1979). Orally introduced Lactobacillus acidophilus must be capable of surviving the transient time spent in the stomach and small intestine. Lactobacillus bulgaricus and Streptococcus thermo-

\footnotetext{
*Corresponding author: Randy W. Worobo, Department of Food Science \& Technology, Cornell University, Geneva, NY 14456, USA, Tel: 1-315-787-2279, Fax: 1-315-787-2284, E-mail: rww8@, cornell.edu
}

philus have previously been shown not to survive residence in the stomach, and thus, not reach the lower small intestine (Robins-Browne and Levine, 1981).

Bile salt induces membrane damage in intestinal bacteria. $L$. acidophilus seems to be able to hydrolysis the bile salts, however, bile salt hydrolase (BSH) has not been detected in bacteria isolated from certain environments where bile is absent, such as plant fermented products (Begley and Levine, 2006).

Some LAB, such as L. acidophilus strains have the ability to assimilate cholesterol during growth in the presence of bile under anaerobic conditions. Klaver and Van der Meer (1993) reported that the cholesterol assimilation may be due to the precipitation of cholesterol with deconjugated bile salts. Deconjugation of bile acids may play an important role in host serum cholesterol levels since deconjugated bile acids do not function as well as conjugated bile acids in the solublization and absorption of lipids. Bile salt hydrolase (BSH) catalyzes the hydrolysis of conjugated bile acids to produce free bile acids and amino acids (Lundeen and Savage, 1990). Thus, the hypocholes- 
teremic effect of L. acidophilus strains should be associated with the production of BSH.

Conjugated linoleic acid (CLA) occurs naturally in a wide variety of foods, especially in dairy foods that are derived from ruminant animals. CLA has been shown to possess anticarcinogenic and antiartherogenic properties which can be consumed without any apparent adverse effects on the host (Parodi, 1999). Thus, CLA production may be a good criterion for the selection of microbial strains to be used as probiotic cultures.

The purpose of this study was to determine cholesterol assimilation ability, acid and bile tolerances, deconjugation of glycocholate and taurocholate, and CLA production of probiotic strains of L. acidophilus.

\section{Materials and Methods}

\section{Bacterial strains}

L. acidophilus strains were obtained from Dairy Microbiology Laboratory in Oklahoma State University. The strains of L. acidophilus were grown for $18 \mathrm{~h}$ at $37^{\circ} \mathrm{C}$ in MRS broth (Difco, USA). The strains were subcultured three times before use. The culture was stored at $-80^{\circ} \mathrm{C}$ in a $10 \%$ skim milk medium supplemented with $30 \%$ glycerol.

\section{Measurement of cholesterol assimilation}

The amount of cholesterol in the cell-free spent broth was determined by the method of Rudel and Morris (1973). A $0.5 \mathrm{~mL}$ aliquot of the sample was added to $3 \mathrm{~mL}$ of $95 \%$ ethanol and $2 \mathrm{~mL}$ of $50 \% \mathrm{KOH}$ followed by heating at $60^{\circ} \mathrm{C}$ for $10 \mathrm{~min}$. Five $\mathrm{ml}$ of hexane was added to the cooled samples, which were then mixed well for $30 \mathrm{~s}$. A $25 \mathrm{~mL}$ aliquot of the hexane layer was dried under a flow of $\mathrm{N}_{2}$ gas. Color was developed by the addition of $o$ phthalaldehyde and concentrated sulfuric acid. Color measurement was determined at a wavelength of $550 \mathrm{~nm}$ using a spectrophotometer (Beckman DU Series 600, Beckman Instruments Inc., USA). The amount of cholesterol was calculated from a standard curve using $0,10,20$, 40 and $80 \mathrm{mg} / \mathrm{mL}$ cholesterol (Sigma Chemical Co., USA).

\section{Acid tolerance}

The strains were incubated at $37^{\circ} \mathrm{C}$ for $18 \mathrm{~h}$ and then centrifuged at $5000 \mathrm{~g}$ for $20 \mathrm{~min}$ at $4^{\circ} \mathrm{C}$. The collected cells were resuspended in sterile saline $(0.85 \% \mathrm{NaCl})$. The cells were inoculated at $c a 10^{6} \mathrm{CFU} / \mathrm{mL}$ in MRS broth adjusted to $\mathrm{pH} 2.5$ with $1 \mathrm{~N} \mathrm{HCl}$ for $1 \mathrm{~h}$. The viable cell count was determined after 0 and $1 \mathrm{~h}$ of incubation at $37^{\circ} \mathrm{C}$. Aliquots $(1 \mathrm{~mL})$ of acid exposed and untreated cell samples were diluted in sterile peptone water and plated onto MRS media containing $2 \%$ b-glycerophosphate, and were allowed to incubate at $37^{\circ} \mathrm{C}$ for $2 \mathrm{~d}$ before enumeration. Acid tolerance was expressed as the log difference of viable cells between treatment and initial levels.

\section{Bile tolerance \& deconjugation activity}

Bile tolerance was determined by inoculating $\left(10^{6}\right.$ $\mathrm{CFU} / \mathrm{mL}$ ) MRS broth containing $0.3 \%$ oxgall (Difco) inoculated with a resuspended culture grown at $37^{\circ} \mathrm{C}$ for $18 \mathrm{~h}$. The bacteria were plated onto MRS media and enumerated after $24 \mathrm{~h}$ of growth at $37^{\circ} \mathrm{C}$. The bile tolerance for each concentration of bile acids was expressed as follows: (Final log number of viable cells) - (Initial log number of viable cells).

The amount of bile salts (sodium glycocholate and sodium taurocholate; Sigma Chemical Co.) deconjugated by $L$. acidophilus strains were determined using HPLC (Waters, USA) on Nova-Pak $\mathrm{C}_{18}$ column (Waters) as described by Corzo and Gilliland (1999). Deconjugation activity was based on the percent reduction of sodium glycocholate and sodium taurocholate from the original medium.

\section{CLA analysis}

Cells grown to an $\mathrm{O} . \mathrm{D}=1$ were used as an inoculum in the experiments. Skim milk $(11 \% \mathrm{w} / \mathrm{v})$ with filter sterilized (0.22 mm, Milipore, Millipore Corp., USA) linoleic acid solution $(0.1 \mathrm{~g} / \mathrm{L}$ final $)$ was used to test CLA production. Samples were extracted and methylated as previously described by Kim and Liu (1999). Fatty acid methyl esters were analyzed by GC (HP5890, Hewlett Packard, USA) on the Supelcowax-10 fused silica capillary column (Supelco Inc., USA). Heptadecanoic acid $\left(\mathrm{C}_{17: 0}\right.$; Sigma Chemical Co.) was used as an internal standard. Cis-9, trans-11 octadecadienoic acid ( $<99 \%$ cis- 9 , trans- 11 isomer; Matreya Inc., USA) was used as the CLA standard.

\section{Statistical analysis}

All experiments were replicated six times and viable cell counts were performed in duplicate. Statistical analysis was performed on data using GLM and CORR procedures with SAS systems (SAS, 2008), to compare within groups and to establish if any relationship existed between the different characteristics. 


\section{Results}

\section{Cholesterol assimilation of $\boldsymbol{L}$. acidophilus strains}

Strains of $L$. acidophilus were tested for their capability of cholesterol assimilation. Among the 12 stains of $\mathrm{L}$. acidophilus, some variation was observed in their ability to assimilate cholesterol. Twelve strains of $L$. acidophilus were classified into three groups (high, medium, and low) statistically, in terms of their degree of cholesterol assimilation (Fig. 1) after which probiotic characteristics were compared within each group.

The strains 4356, 30SC, 393, and 4962 were classified as the low assimilation group, within which cholesterol assimilation ranged from $28 \%$ to $36 \%$. Strains $107 \mathrm{~A}$ and GP4A, the medium assimilation group, showed $48.2 \%$ and $47.1 \%$ cholesterol assimilation, respectively. In the case of the high assimilation group, cholesterol assimilation was greater than $50 \%$ for the strains 43121, GP2A, GP1B, A4, NCFM, and 606.

\section{Comparison of probiotic characteristics}

Table 1 summarizes the comparison of cholesterol as-

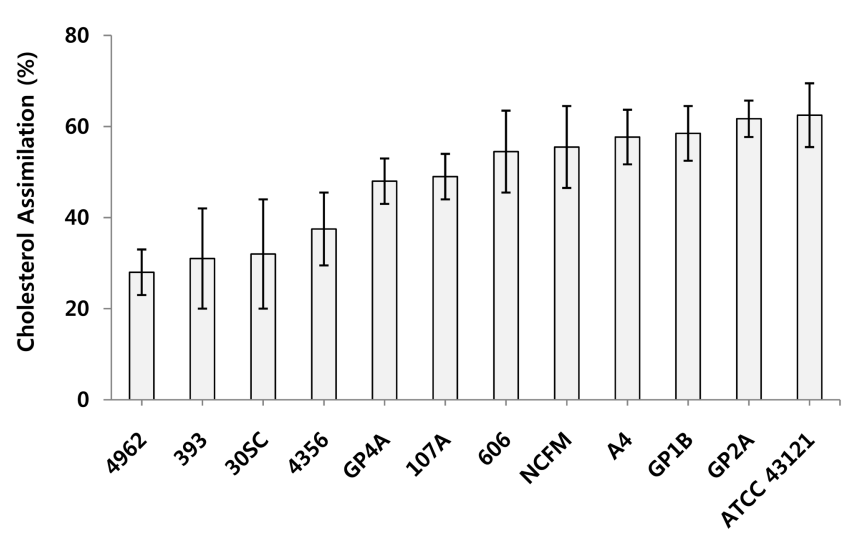

Fig 1. Cholesterol assimilation by Lactobacillus acidophilus strains in the cell-free spent MRS broth. similation, bile ( 0.3 and $0.5 \%)$ tolerances, acid tolerance, deconjugation activities and CLA production by the 3 groups. The high cholesterol assimilation group showed a higher tolerance to $0.3 \%$ and $0.5 \%$ oxgall than either the medium or low assimilation groups $(p<0.05)$, whereas the low cholesterol assimilation group showed a higher acid tolerance than the high and medium assimilation groups $(p<0.05)$.

After incubation in bile acid supplemented media for $24 \mathrm{~h}$, the viable cell counts in the high assimilation group showed a slight increase with $1.48 \log$ and $0.93 \log$ in $0.3 \%$ and $0.5 \%$ bile acids, respectively.

All 12 strains of $L$. acidophilus studied were shown to be able to deconjugate glycocholate and taurocholate. There were no significant differences in the reduction of glycocholate and taurocholate among the three cholesterol assimilation groups of L. acidophilus strains. However, the high assimilation group showed the lowest reduction of glycocholate and taurocholate.

\section{CLA production}

All 12 strains of L. acidophilus were assessed for CLA

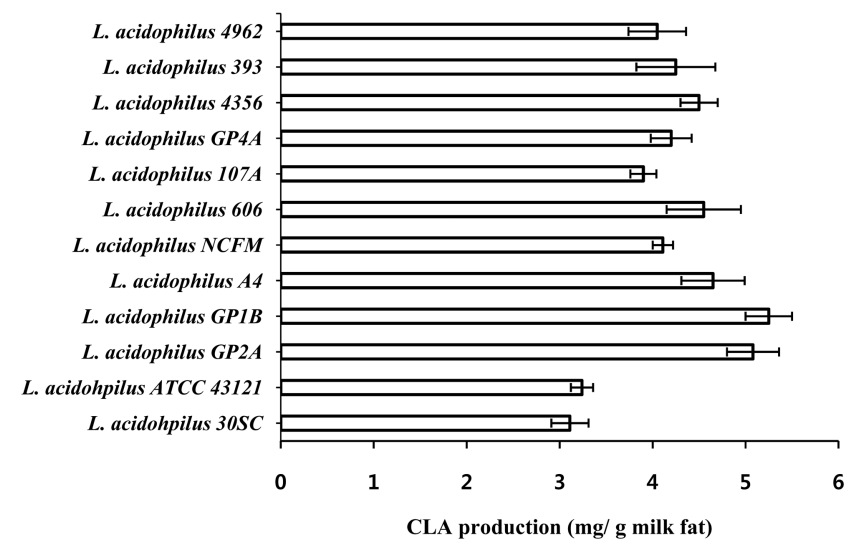

Fig. 2. Concentration of conjugated linoleic acid by $L$. acidophilus strains in $11 \%$ skim milk medium.

Table 1. Comparison of cholesterol assimilation, bile and acid tolerances, and reduction of glycocholate and taurocholate by Lactobacillus acidophilus strains

\begin{tabular}{lrrr}
\hline \hline & High Group & Medium Group & Low Group \\
\hline Cholesterol assimilation & $57.98^{\mathrm{a}}(6.152)^{*}$ & $47.70^{\mathrm{b}}(4.080)$ & $31.736^{\mathrm{c}}(7.996)$ \\
$0.3 \%$ Bile tolerance & $1.48^{\mathrm{a}}(0.447)$ & $1.16^{\mathrm{ab}}(0.532)$ & $1.03^{\mathrm{b}}(0.923)$ \\
$0.5 \%$ Bile tolerance & $0.93^{\mathrm{a}}(0.846)$ & $1.18^{\mathrm{a}}(0.702)$ & $0.18^{\mathrm{b}}(1.136)$ \\
Acid tolerance & $-0.18^{\mathrm{a}}(0.172)$ & $-0.21^{\mathrm{a}}(0.111)$ & $0.03^{\mathrm{b}}(0.397)$ \\
Reduction \% of glycocholate & $30.54^{\mathrm{a}}(5.482)$ & $31.38^{\mathrm{a}}(5.397)$ & $40.86^{\mathrm{a}}(12.660)$ \\
Reduction \% of taurocholate & $44.86^{\mathrm{a}}(5.839)$ & $50.98^{\mathrm{a}}(8.649)$ & $57.53^{\mathrm{a}}(9.300)$ \\
CLA production (mg/milk fat g) & $4.55^{\mathrm{a}}(0.354)$ & $4.1^{\mathrm{a}}(0.141)$ & $4.26^{\mathrm{a}}(0.357)$ \\
\hline
\end{tabular}

*Means with standard error in parentheses

${ }^{\mathrm{a}, \mathrm{b}, \mathrm{c}}$ Means with the same superscript are not significantly different $(p<0.05)$.

Comparisons are made within same row for means. 
Table 2. Correlation coefficients of probiotic characteristics of Lactobacillus acidophilus strains

\begin{tabular}{lccrrrrr}
\hline \hline & $\begin{array}{c}\text { Cholesterol } \\
\text { assimilation }\end{array}$ & $\begin{array}{l}0.3 \% \text { Bile } \\
\text { tolerance }\end{array}$ & $\begin{array}{l}0.5 \% \text { Bile } \\
\text { tolerance }\end{array}$ & $\begin{array}{c}\text { Acid } \\
\text { tolerance }\end{array}$ & $\begin{array}{r}\text { Reduction of } \\
\text { glycocholate }\end{array}$ & $\begin{array}{l}\text { Reduction of } \\
\text { taurocholate }\end{array}$ & $\begin{array}{c}\text { CLA } \\
\text { Production }\end{array}$ \\
\hline Cholesterol assimilation & $1.0(0.0)^{*}$ & $0.212(0.075)$ & $0.333(0.004)$ & $-0.346(0.003)$ & $-0.138(0.422)$ & $-0.327(0.051)$ & $0.009(0.977)$ \\
0.3\% Bile tolerance & & $1.0(0.000)$ & $0.601(0.001)$ & $-0.450(0.001)$ & $0.119(0.490)$ & $-0.100(0.577)$ & $-0.102(0.752)$ \\
0.5\% Bile tolerance & & & $1.0(0.000)$ & $-0.494(0.001)$ & $0.215(0.208)$ & $0.122(0.461)$ & $0.024(0.940)$ \\
Acid tolerance & & & & $1.0(0.000)$ & $-0.134(0.436)$ & $-0.020(0.909)$ & $-0.101(0.754)$ \\
Reduction of glycocholate & & & & & $1.0(0.000)$ & $0.220(0.197)$ & $-0.123(0.704)$ \\
Reduction of taurocholate & & & & & & $1.000(0.000)$ & $0.217(0.497)$ \\
\hline
\end{tabular}

*The values in parentheses are $p$-value.

production. The results from the comparison of $L$. acidophilus cultures for CLA production are shown in Fig. 2. L. acidophilus strains were capable of producing CLA in the range of 3.24 to $5.04 \mathrm{mg} / \mathrm{g}$ fat. No differences in CLA production were found among the three groups. L. acidophilus GP1B exhibited the highest CLA production for all the strains tested

\section{Relationship of probiotic characteristics}

A summary of correlation coefficients for probiotic characteristics is presented in Table 2. The cholesterol assimilation showed positive correlation with $0.3 \%$ and $0.5 \%$ bile tolerances $(p<0.01)$ and negative correlation with acid tolerance $(p<0.01)$. Acid tolerance exhibited significant negative correlation with $0.3 \%$ bile tolerance $(\mathrm{r}=-0.45)$ and $0.5 \%$ bile tolerance $(\mathrm{r}=-0.494)$. The reduction of glycocholate and taurocholate showed negative correlations with cholesterol assimilation among the strains tested. CLA production showed no correlation with cholesterol assimilation.

\section{Discussion}

L. acidophilus are a genetically heterogeneous species, and their classification has been a difficult task. DNA homology led to the identification of six major species: $L$. crispatus, L. amylovorus, L. gallinarum, L. gasseri, $L$. johnsonii, and $L$. acidophilus which exhibit clear distinctions from one another, but constitute the same $L$. acidophilus group (Hammes and Vogel, 1995).

Of the probiotic LAB, L. acidophilus was the first bacterium suggested to have a cholesterol-lowering effect in humans and animals. Several studies involving rats (Akakin et al., 1997), pigs (de Rodas et al., 1996), and humans (Schaafsma et al., 1996), that were fed L. acidophilus cultured products or diets containing L. acidophilus, showed a significant reduction in blood cholesterol levels. Bile is produced in the liver from various substrates, including cholesterol. The liver turns cholesterol into cholic and deoxycholic acids that combine with glycine and taurine (Brandt and Bernstein, 1976). Gilliland et al. (1985) reported that when L. acidophilus was grown in the presence of cholesterol, some of the cholesterol was incorporated into the $L$. acidophilus cells while they were growing.

Like as $L$. acidophilus strains, Bifidobacterium species have the ability to remove cholesterol from the medium involved as assimilation of cholesterol in the cells and a precipitation of cholesterol with deconjugated bile salts. Tahri et al. (1997) reported that a low amount of cholesterol was assimilated by the Bifidobacterium breve ATCC 15700 in the absence of bile acids, whereas in the presence of $0.3 \%$ of oxgall, 4 -fold more cholesterol was assimilated from the broth medium. They concluded that bile salts were involved in the assimilation of cholesterol.

Noh et al. (1997) reported similar results with L. gasseri strains, showing that these strains exhibited a high binding activity to cholesterol but these strains were very sensitive to bile acid, as indicated by the extended delay of growth. It was suggested that the cell membrane was involved in the binding of cholesterol. Walker and Gilliland (1993) reported that there were no significant correlations between bile tolerance, bile salt deconjugation and cholesterol assimilation in 19 tested strains of L. acidophilus, because of the high variation observed. Cholesterol assimilation by lactobacilli was found to be due to bacterial bile salt-deconjugating activity, and not due to the bacterial uptake of cholesterol.

Within this study, cholesterol reduction by L. acidophilus strains exhibited a significant $(p<0.01)$ correlation between bile tolerance and cholesterol assimilation, which was not related to deconjugation activity. Furthermore, cholesterol assimilation of $L$. acidophilus strains showed a negative correlation with taurocholate deconjugation $(p<0.05)$.

It appears that the activity of cholesterol assimilation may be related to bile acid tolerance, but not to deconju- 
gation activity. The possibility of strain variation was not completely ruled out, but the level of cholesterol assimilation appears to have a correlation with bile resistance. Further research is required in order to fully understand the mechanism of cholesterol assimilation in L. acidophilus strains.

\section{Conclusions}

Twelve strains of Lactobacillus acidophilus, isolated from feces of human or animal sources, were tested for the probiotic properties of cholesterol assimilation, bile and acid tolerances, and CLA production. Although the cultures showed some variation with respect to each test, the 12 strains could be classified into 3 significantly differentiated groups based on their ability to assimilate cholesterol. Cholesterol assimilation ability showed a positive correlation with bile tolerance, and a negative correlation with acid tolerance. The cholesterol assimilation ability of L. acidophilus strains may not be related to deconjugation activity, but may in-fact be attributed to their bile-tolerance.

\section{Acknowledgments}

This study was supported by Culture Systems Inc., Mishawaka, IN, USA.

\section{References}

1. Akalin, A. S., Gönç, S., and Düzel, S. (1997) Influence of yogurt and acidophilus yogurt on serum cholesterol levels in mice. J. Dairy Sci. 80, 2721-2725.

2. Begley, M., Hill, C., and Gahan, C. G. M. (2006) Bile salt hydrolase activity in probiotics. Appl. Environ. Microbiol. 72, 1729-1738.

3. Brandt, L. J. and Bernstein, L. H. (1976) Bile salts: their role in cholesterol synthesis, secretion and lithogenesis. Am. J. Gastroenterol. 65, 17-30.

4. Corzo, G. and Gilliland, S. E. (1999) Measurement of bile salt hydrolase activity from Lactobacillus acidophilus based on disappearance of conjugated bile salts. J. Dairy Sci. 82, 466-471.

5. de Rodas BZ, Gilliland, S. E., and Maxwell, C. V. (1996) Hypocholesterolemic action of Lactobacillus acidophilus ATCC 43121 and calcium in swine with hypercholester- olemia induced by diet. J. Dairy Sci. 79, 2121-2128.

6. Gilliland, S. E. (1979). Beneficial interrelationships between certain microorganisms and humans: candidate microorganisms for use as dietary adjuncts. J. Food Prot. 42, 164-167.

7. Gilliland, S. E., Nelson, C. R., and Maxwell, C. (1985) Assimilation of cholesterol by Lactobacillus acidophilus. Appl. Environ. Microbiol. 49, 377-381.

8. Hammes, W. P. and Vogel, R. F. (1995) The genus Lactobacillus. In: The lactic acid bacteria Volumn 2 The genera of lactic acid bacteria. Wood, B. J. B. and Holzapfel, W. H. (ed) Blackie Academic and Professional, London, pp. 19-53.

9. Havenaar, R., Brink, B. T., and Huis in't Veld, J. H. J. (1992) Selection of strains for probiotic use. In: Probiotics. Fuller, R (ed) Champman \& Hall, London, pp. 209-224.

10. Kim, Y. J. and Liu, R. H. (1999) Selective increase in conjugated linoleic acid in milk fat by crystallization. J. Food Sci. 64, 792-795.

11. Klaver, F. A. M. and Van der Meer, R. (1993) The assumed assimilation of cholesterol by Lactobacilli and Bifidobacterium bifidum is due to their bile salt-deconjugation activity. Appl. Environ. Microbiol. 59, 1120-1124.

12. Lundeen, S. G. and Savage, D. C. (1990) Characterization and purification of bile salt hydrolase from Lactobacillus sp. strain 100. J. Bacteriol. 172, 4171-4177.

13. Noh, D. O., Kim, S. H., and Gilliland, S. E. (1997) Incorporation of cholesterol into cellular membrane of Lactobacillus acidophilus ATCC 43121. J. Dairy Sci. 80, 3107-3113.

14. Parodi, P. W. (1999) A bold new look at milk fat; conjugated linoleic acid and other anticarcinogenic agents of bovine milk fat. J. Dairy Sci. 82, 1339-1349.

15. Robins-Browne, R. M. and Levine, M. M. (1981) The fate of ingested lactobacilli in the proximal small intestine. Am. J. Clin. Nutr. 34, 514-519.

16. Rudel, L. L. and Morris, M. D. (1973) Determination of cholesterol using $o$-phthalaldehyde. J. Lipid Res. 14, 364-366.

17. SAS (2008) SAS/STAT software for PC. Release 9.2, SAS Institute Inc., Cary, NC, USA.

18. Schaafsma, G., Meuling, W. J. A., and van Dokkum, W. (1996) Nieuw zuivelprodukt gefermentteerd met Lactbacillus acidophilus. Zuivel kan serumcholesterol verlagen. Voeding 57, 12-14.

19. Tahri, K., Grill, J. P., and Schneider, F. (1997) Involvement of trihydroxyconjugated bile salts in cholesterol assimilation by bifidobacteria. Curr. Mirobiol. 34, 79-84.

20. Walker, D. K., and Gilliland, S. E. (1993) Relationships among bile tolerance, bile salt deconjugation, and assimilation of cholesterol by Lactobacillus acidophilus. J. Dairy Sci. 76, 956-961.

(Received 2012.1.9/Revised 2012.4.23/Accepted 2012.6.8) 